\title{
Partial rescue of Rett syndrome by $\omega-3$ polyunsaturated fatty acids (PUFAs) oil
}

\author{
Claudio De Felice - Cinzia Signorini - Thierry Durand - Lucia Ciccoli • \\ Silvia Leoncini - Maurizio D'Esposito · Stefania Filosa • Camille Oger • \\ Alexandre Guy · Valérie Bultel-Poncé · Jean-Marie Galano · Alessandra Pecorelli • \\ Laura De Felice $\cdot$ Giuseppe Valacchi $\cdot$ Joussef Hayek
}

Received: 6 December 2011/ Accepted: 30 January 2012/Published online: 8 March 2012

(c) Springer-Verlag 2012

\begin{abstract}
Evidence of enhanced oxidative stress (O.S.) and lipid peroxidation has been reported in patients with Rett syndrome (RTT), a relatively rare neurodevelopmental disorder progressing in 4-stages, and mainly caused by loss-of-function mutations in the methyl-CpG-binding protein 2. No effective therapy for preventing or arresting the neurologic regression in the disease in its various clinical presentations is available. Based on our prior evidence of enhanced O.S. and lipid peroxidation in RTT patients, herein we tested the possible therapeutic effects of $\omega-3$ polyunsaturated fatty acids ( $\omega-3$ PUFAs), known antioxidants with multiple effects, on the clinical
\end{abstract}

Claudio De Felice, Cinzia Signorini and Joussef Hayek are contributed equally to this work.

Electronic supplementary material The online version of this article (doi:10.1007/s12263-012-0285-7) contains supplementary material, which is available to authorized users.

\section{De Felice $(\square)$}

Neonatal Intensive Care Unit, University Hospital Azienda Ospedaliera Universitaria Senese (AOUS) of Siena, S. M. Le Scotte General Hospital, Viale M. Bracci, 16, 53100 Siena, Italy e-mail: geniente@gmail.com

C. Signorini $\cdot$ L. Ciccoli $\cdot$ S. Leoncini $\cdot$ A. Pecorelli Department of Pathophysiology, Experimental Medicine and Public Health, University of Siena, Siena, Italy

T. Durand · C. Oger · A. Guy · V. Bultel-Poncé · J.-M. Galano Institut des Biomolécules Max Mousseron (IBMM), UMR 5247 CNRS, UM I, UM II, Montpellier, France

M. D’Esposito · S. Filosa

Institute of Genetics and Biophysics "Adriano Buzzati

Traverso" CNR, Napoli, Italy

M. D'Esposito · S. Filosa

IRCCS Neuromed, Pozzilli, Italy symptoms and O.S. biomarkers in the earliest stage of RTT. A total of 20 patients in stage I were randomized ( $n=10$ subjects per arm) to either oral supplementation with $\omega$-3 PUFAs-containing fish oil (DHA: $72.9 \pm 8.1 \mathrm{mg}$ / $\mathrm{kg}$ b.w./day; EPA: $117.1 \pm 13.1 \mathrm{mg} / \mathrm{kg}$ b.w./day; total $\omega-3$ PUFAs: $246.0 \pm 27.5 \mathrm{mg} / \mathrm{kg}$ b.w./day) for 6 months or no treatment. Primary outcomes were potential changes in clinical symptoms, with secondary outcomes including variations for five O.S. markers in plasma and/or erythrocytes (nonprotein bound iron, $\mathrm{F}_{2}$-dihomo-isoprostanes, $\mathrm{F}_{3}$-isoprostanes, $\mathrm{F}_{4}$-neuroprostanes, and $\mathrm{F}_{2}$-isoprostanes). A significant reduction in the clinical severity (in particular, motor-related signs, nonverbal communication deficits, and breathing abnormalities) together with a significant decrease in all the examined O.S. markers was observed in the $\omega-3$ PUFAs supplemented patients, whereas no significant changes were evidenced in the untreated group. For the first time, these findings strongly suggest that a dietary

L. De Felice

Multimedia Content Design Master Course,

University of Florence, Florence, Italy

G. Valacchi

Department of Evolutionary Biology,

University of Ferrara, Ferrara, Italy

G. Valacchi

Department of Food and Nutrition,

Kyung Hee University, Seoul, Korea

J. Hayek

Child Neuropsychiatry Unit, University Hospital,

AOUS, Siena, Italy 
intervention in this genetic disease at an early stage of its natural history can lead to a partial clinical and biochemical rescue.

Keywords Rett syndrome - MeCP2 - Oxidative Stress . $\omega-3$ polyunsaturated fatty acids · Isoprostanes · Nonprotein bound iron - Antioxidants

\section{Abbreviations}

$\begin{array}{ll}\text { AA } & \text { Arachidonic acid } \\ \text { AdA } & \text { Adrenic acid } \\ \text { CDKL5 } & \text { Cyclin-dependent kinase-like 5 } \\ \text { F }_{2} \text {-dihomo-IsoPs } & \text { F }_{2} \text {-dihomo-isoprostanes } \\ \text { FOXG1 } & \text { Forkhead box G1 } \\ \text { GC/NICI-MS/MS } & \text { Gas chromatography/negative ion } \\ & \text { chemical ionization tandem } \\ & \text { mass spectrometry } \\ \text { IsoPs } & \text { Isoprostanes } \\ \text { MeCP2 } & \text { Methyl-CpG-binding protein 2 } \\ \text { NPBI } & \text { Nonprotein bound iron } \\ \text { O.S. } & \text { Oxidative stress } \\ \text { RTT } & \text { Rett syndrome }\end{array}$

\section{Introduction}

Loss-of-function mutations of the X-linked gene methylCpG-binding protein 2 (MeCP2) are responsible for $90-95 \%$ of classical Rett syndrome (RTT) (Amir et al. 1999), the second most common cause of severe mental retardation in females (Rett 1966; Hagberg et al. 1983). RTT occurs with a frequency of up to $1 / 10,000$ live female births. Typically, after an apparently normal development for 6-18 months, RTT girls lose their acquired cognitive, social, and motor skills in a typical 4-stage neurologic regression (Hagberg et al. 1983; Leoncini et al. 2011) and develop autistic behavior accompanied by stereotypic hands movements. Further deterioration leads to severe mental retardation and motor impairment, including ataxia, apraxia, and tremors. Seizures, hyperventilation, and apneas are also common (Chahrour and Zoghbi 2007). A portion of RTT patients with no MeCP2 mutation has been found mutated in related genes such as cyclin-dependent kinase-like 5 (CDKL5) (Mari et al. 2005), interacting with MeCP2 and Forkhead box G1 (FOXG1) for the congenital form (Ariani et al. 2008). To date, no effective therapy for preventing or arresting the neurologic regression in the disease in its various clinical presentations is available. The anatomical equivalent of MeCP2 deficiency is a reduced brain size possibly due to decreases in major brain regions such as the frontal and temporal lobes, caudate nucleus, thalamus, midbrain, and cerebellum, all of which have been documented in RTT patients, while at the cellular level, the neuronal soma is smaller in the absence of $\mathrm{MeCP} 2$, and cells are more densely packed. Postsynaptic morphological defects (i.e., reduced dendritic branching, reduced dendritic spine density, and defects in spine morphology) and presynaptic abnormalities, such as abnormal number of axons and a defect in axonal targeting overall resulting in a decrease in the number of synapses in RTT brains with an abnormal excitatory/inhibitory balance, with increased excitatory and decreased inhibitory neurotransmission in the hippocampus and cortex and the brainstem, have been reported (for a comprehensive review of these among other aspects of MeCP2 deficiency see Guy et al. 2011). Overall, the evidence in both MeCP2deficient patients and mice implies that loss of MeCP2 causes malfunction of numerous synapses throughout the brain, which creates less efficient neuronal networks and gives rise to RTT-like phenotypes. Furthermore, data from mice lacking MeCP2 from $\gamma$-amino-butyric-acid-(GABA)ergic neurons demonstrate that $\mathrm{MeCP} 2$ is critical for normal GABAergic neuronal function and that subtle dysfunction of GABAergic neurons contributes to numerous neuropsychiatric phenotypes (Chao et al. 2010). However, despite almost two decades of research into the functions and role of $\mathrm{MeCP} 2$, to date, surprisingly little is known on the mechanisms leading from MeCP2 deficiency to disease expression, with several questions regarding the role of $\mathrm{MeCP} 2$ in the brain being yet to be answered conclusively (Guy et al. 2011), and even the concept of RTT as a pure neuronal disease has been questioned (Zoghbi 2009). MeCP2, a key transcription regulator, is critically involved in DNA methylation (Macdonald et al. 2010). It is generally believed that MeCP2 through association with co-repressors is able to repress transcription, even if it has been reported to be able to activate transcription in specific brain districts (Chahrour et al. 2008; Ben-Shachar et al. 2009).

At the therapeutic level, a critical notion is the potential reversibility of RTT symptoms in mouse models (Guy et al. 2007), corroborating the findings that patients do not show neuronal death and emphasizing the hypothesis that $\mathrm{MeCP} 2$ is required to stabilize and maintain the mature neuronal state. This was proved by studying a mouse model in which $\mathrm{MeCP} 2$ reexpression was inducible in an agerelated fashion. Postnatal $\mathrm{MeCP} 2$ activation in null mice eliminate all RTT-like symptoms, making treated mice indistinguishable from wild-type ones. These studies provide valuable insights into the possible "manipulation" of RTT clinical signs and are useful pointers for the development of future therapeutic strategies (Cobb et al. 2010). However, similar strategies cannot be easily applicable to human RTT for two main reasons: first patients are mosaics, having half of their cells expressing MeCP2 at wild-type level due to $\mathrm{X}$ inactivation; an indiscriminate excess of the protein can affect their health as well as its 
absence (Matarazzo et al. 2009), as observed also in mice models overexpressing MeCP2 (Collins et al. 2004).

To better understand the biological bases of the syndrome at the molecular level, RTT models can potentially help to elucidate the relationships between DNA methylation and disease expression and could generate new perspectives on disease treatment. Several molecules (desipramine, ampakine, IGF1) (Ogier et al. 2007; Roux et al. 2007; Tropea et al. 2009) or strategies (e.g., gene therapy) (Guy et al. 2007) have been suggested to either improve or partially reverse clinical symptoms in RTT patients. Given that MeCP2 null mice show respiratory rhythm disturbances, which are usually ascribed to alterations in brainstem neurons (Viemari et al. 2005), some pharmacological treatments have been proved effective in antagonizing respiratory symptoms in mouse models of the disease, frequent (26\% of the cases) cause of death in RTT patients, although their mechanisms of action remain obscure.

Replacement therapy with recombinant TAT- MeCP2 proteins (Laccone, pers. commun.) and the use of somatic cells that can be reprogrammed into induced pluripotent stem cells (iPSCs) (Marchetto et al. 2010) hold promise as a potential cure of the disease in a foreseeable future.

Our group has recently demonstrated a condition of systemic oxidative stress (O.S.) and lipid peroxidation in human patients with typical RTT, along with persistent hypoxia and lung oxygen exchange impairment (De Felice et al. 2009).

O.S. is involved in the pathogenic mechanisms of several neurodevelopmental and neurodegenerative disorders (Halliwell and Gutteridge 1999), and it is well established that membrane lipids containing long-chain polyunsaturated fatty acids are primary targets for reactive oxygen species (ROS) attack (Morrow et al. 1990; Yin and Porter 2005). Isoprostanes (IsoPs), isomers of cyclooxygenasederived prostaglandins (PGs), are one of the major classes of lipid peroxidation products generated from the membrane lipids by free radical reactions (Morrow and Roberts 1997). In particular, analysis of $F_{2}$-IsoPs, formed by free radical-catalyzed peroxidation of phospholipid-bound arachidonic acid (AA, C20:4 $\omega-6$ ), has been regarded as the gold standard to assess the O.S. status (Wood et al. 2003; Montine et al. 2004; Montuschi et al. 2004; Comporti et al. 2008; Nourooz-Zadeh 2008; Kadiiska et al. 2005).

$\omega-3$ polyunsaturated fatty acids ( $\omega-3$ PUFAs) are attracting emerging interest as antioxidants due to their multiple therapeutical effects and safe use (Lien 2009). In particular, eicosapentaenoic acid (EPA, 20:5 $\omega-3$ ) and docosahexaenoic acid (DHA, 22:6 $\omega-3$ ), the major $\omega-3$ PUFAs contained in fish oil, have anti-inflammatory, antithrombotic, vasodilator, hypolipidemic, and anti-arrhythmic properties, thus exerting potential pleiotropic beneficial effects on cardiovascular function (Kris-Etherton et al. 2002) and in experimental brain hypoxia (Belayev et al.
2009). More recently, a protective effect of $\omega-3$ PUFAs on developmental neurotoxicity has also been reported (El-Ansary et al. 2011).

During the natural progression of RTT, certainly, stage I is the most dramatic event, characterized by a neurologic regression in an apparently normally developing girl of 6 to 18 months. Herein, we tested the possible actions of a relatively short-term $\omega-3$ PUFAs oil supplementation in RTT patients in stage I on clinical and on validated lipid peroxidation biomarkers of O.S.

\section{Methods}

\section{Study population}

A total of 20 consecutively admitted female RTT patients in stage I were recruited. Inclusion criteria were clinical diagnosis of RTT syndrome in stage I and absence of RTT exclusion criteria (Neul et al. 2010), and demonstration of $\mathrm{MeCP} 2$ mutation or deletion. Compliance to the supplementation was monitored by their general pediatricians, previously informed about the clinical trial. We decided not to include patients with RTT variants as, (a) in our clinical series, they contribute for a relatively low fraction of the total RTT patients, and (b) because of the raising concern that RTT variants linked to CDKL5 or FOXG1 gene mutations may actually represent RTT-like diseases rather than true clinical variants of the disease (Naidu and Johnston 2011), as further suggested by the significantly different entity of O.S. in patients with RTT variants (Pecorelli et al. 2011; Leoncini et al. 2011; Signorini et al. 2011).

Gender- and age-matched controls were also enrolled in the study. Blood samplings in the control group were carried out during routine health checks.

\section{Study design}

The experimental design was randomized, single center, and single blind. Patients were randomized at admission ( $n=10$ treated, mean age at supplementation time zero: $21 \pm 6.6$ months; $n=10$ untreated, mean age at time zero: $20.4 \pm 7.3$ months) to either oral supplementation with $\omega$-3 PUFAs oil for 6 months or no treatment.

Use of EPA plus DHA in RTT was approved by the AOUS Ethical Committee.

All the subjects, included patients, examined in this study were following a standard Mediterranean diet.

\section{Primary outcomes}

Primary outcomes were potential changes in clinical symptoms following supplementation with $\omega-3$ PUFAs. 
RTT clinical severity was assessed using the clinical severity score (CSS), a validated clinical rating specifically designed for RTT (Neul et al. 2008), based on 13 individual, ordinal categories measuring clinical features common in RTT. All scores range from 0 to 4 or 0 to 5 with 0 representing the least severe and 4 or 5 representing the most severe finding. A series of individual clinical items of interest were also evaluated to compress the ordinal category measures into a binary measurement with 0 representing "mild" or "retained function" and 1 representing "severe" or "lost/absent function." Mild or retained functions were considered in the case of neurologic regression after 18 months of life, weight decrease $<2 \mathrm{SD}$, head circumference greater than the 10th percentile after 24 months of life, sitting maintained; independent walking; hands use at least partially conserved, scoliosis $<20^{\circ}$ : use of at least single words, maintained eye contact for at least $5 \mathrm{~s}$, presence of minimal respiratory dysfunction $(<10 \%$ of the time), stereotypy onset after 36 months of life, and seizures absent or less than monthly. In order to better quantify the specific CSS variable "respiratory dysfunction" a respiratory polygraphic study during wakefulness and sleep (polysomnography) was carried out in all patients (Somnowatch plus, Somnomedics, Italian importer Linde Medicale srl).

At the follow-up visits, the RTT parents were encouraged to bring their personal homemade video clips and/or pictures regarding their daughters with images comparing the time before with the time after $\omega$-3 PUFAs supplementation, and informed consent for using private images for scientific purposes was obtained.

\section{Secondary outcomes}

Secondary outcomes were the potential reduction in O.S. markers in plasma and/or erythrocytes following supplementation with $\omega-3$ PUFAs. The markers included nonprotein bound iron (NPBI) (pro-oxidant factor) (Comporti et al. 2002), $\mathrm{F}_{2}$-IsoPs (end-oxidation products of AA; marker in vivo of O.S./systemic lipoperoxidation) (Morrow and Roberts 1997), $\mathrm{F}_{2}$-dihomo-IsoPs (end-oxidation products of adrenic acid, AdA, C22:4 $\omega-6$, marker of glia membrane damage/brain white matter) (VanRollins et al. 2008; De Felice et al. 2011), $\mathrm{F}_{3}$-IsoPs (end-oxidation products of EPA, lipoperoxidation marker) (Yin et al. 2009), and $\mathrm{F}_{4}$-NeuroPs (end-oxidation products of DHA; marker of neuronal membrane damage/brain gray matter) (Roberts et al. 1998; Signorini et al. 2011).

\section{$\omega-3$ PUFAs}

Administered $\omega-3$ PUFAs were in the form of fish oil (Norwegian Fish Oil AS, Trondheim, Norway, Product Number HO320-6; Italian importer: Transforma AS Italia.
Forlimpopoli (FC). Italy; Italian Ministry Registration Code: $1043863-\mathrm{Y}$ ) at a dose of $5 \mathrm{ml}$ twice daily, corresponding to DHA, $72.9 \pm 8.1 \mathrm{mg} / \mathrm{kg}$ b.w./day; EPA, $117.1 \pm 13.1 \mathrm{mg} / \mathrm{kg}$ b.w./day; with a total $\omega-3$ PUFAs, $246.0 \pm 27.5 \mathrm{mg} / \mathrm{kg}$ b.w./day.

We report below the chemical composition of the Norwegian Fish Oil (NFO) liquid composition as communicated by the Norwegian Fish Oil AS Company, Trondheim, Norway:

\begin{tabular}{lc}
\hline Active ingredients: & (Data per 5 mL) \\
\hline EPA (Eicosapentaenoic acid) & $784 \mathrm{mg}$ \\
DHA (Docosahexaenoic acid) & $488 \mathrm{mg}$ \\
Total Omega-3 fatty acids & $1,647 \mathrm{mg}$ \\
\hline
\end{tabular}

Average peroxide levels are reported to be 1.9 (mEq. $0.2 / \mathrm{kg}$ ). The Norwegian Fish Oil liquid is added with natural antioxidants as natural mixed tocopherols concentrate (Covi-Ox T-70 EU). The NFO liquid is reported to be deodorized by an advanced method in the refining process, cleaned of heavy metals, PCB, and dioxin, with concentrations 8-10 times lower than the maximum allowed levels recommended by the European Commission.

\section{Blood sampling}

Blood sampling was carried out in all subjects at around 8.00 AM after the overnight fast. For the $\omega-3$ PUFAstreated group, blood sampling was performed the day before starting the supplementation and the day after the end of the selected 6-month period.

Blood was collected in heparinized tubes, and all manipulations were carried out within $2 \mathrm{~h}$ after collection. Blood samples were centrifuged at $2,400 \times g$ for $15 \mathrm{~min}$ at room temperature. The platelet poor plasma was saved, and the buffy coat was removed by aspiration. The erythrocytes were washed twice with physiological solution, resuspended in Ringer solution $\left(125 \mathrm{mM} \mathrm{NaCl}, 5 \mathrm{mM} \mathrm{KCl}, 1 \mathrm{mM} \mathrm{MgSO}_{4}\right.$, $32 \mathrm{mM}$ HEPES, $5 \mathrm{mM}$ glucose, $1 \mathrm{mM} \mathrm{CaCl}_{2}$ ), pH 7.4 as a $50 \%$ ( $\mathrm{vol} / \mathrm{vol}$ ) suspension, and then used for the determination of erythrocyte Desferioxamine (DFO)-chelatable free iron. Plasma was used for free $\mathrm{F}_{2}$-IsoPs, $\mathrm{F}_{3}$-IsoPs, $\mathrm{F}_{4}$-NeuroPs, $\mathrm{F}_{2}$-dihomo-IsoPs, and DFO-chelatable free iron determinations. For all isoprostane determinations, butylated hydroxytoluene (BHT) $(90 \mu \mathrm{M})$ was added to plasma as an antioxidant and stored under nitrogen at $-70^{\circ} \mathrm{C}$ until analysis.

Intra-erythrocyte and plasma NPBI

Intra-erythrocyte and plasma NPBI were determined as a desferrioxamine (DFO)-iron complex by high-performance liquid chromatography, as previously reported (De Felice et al. 2009). 
Isoprostanes (IsoPs)

$\mathrm{F}_{2}$-IsoPs, $\mathrm{F}_{3}$-IsoPs, $\mathrm{F}_{4}$-NeuroPs, and $\mathrm{F}_{2}$-dihomo-IsoPs were determined by a gas chromatography/negative ion chemical ionization tandem mass spectrometry (GC/NICI-MS/ MS) analysis after solid-phase extraction and derivatization steps.

Each plasma sample was spiked with tetradeuterated prostaglandin $\mathrm{F}_{2 \alpha}\left(\mathrm{PGF}_{2 \alpha}-\mathrm{d}_{4}\right)(500 \mathrm{pg}$ in $50 \mathrm{ml}$ of ethanol), as an internal standard. After acidification $(2 \mathrm{ml}$ of acidified water, $\mathrm{pH} 3$ ), the extraction and purification procedure were carried out. It consisted of two solid-phase separation steps: an octadecylsilane $\left(\mathrm{C}_{18}\right)$ cartridge followed by an aminopropyl $\left(\mathrm{NH}_{2}\right)$ cartridge. The carboxylic group was derivatized as the pentafluorobenzyl ester, whereas the hydroxyl groups were converted to trimethylsilyl ethers. (Nourooz-Zadeh et al. 1995; Signorini et al. 2003).

For $\mathrm{F}_{2}$-IsoPs, the measured ions were the product ions at $\mathrm{m} / \mathrm{z} 299$ and $\mathrm{m} / \mathrm{z} 303$ derived from the [M-181] ${ }^{-}$precursor ions $(\mathrm{m} / z 569$ and $\mathrm{m} / \mathrm{z}, 573)$ produced from $15-\mathrm{F}_{2 \mathrm{t}}$-IsoPs and $\mathrm{PGF}_{2 \alpha}-\mathrm{d}_{4}$, respectively (Signorini et al. 2003).

Quantification of $\mathrm{F}_{3}$-IsoPs was performed by gas chromatography/negative ion chemical ionization tandem mass spectrometry (GC/NICI-MS/MS) according to a new method recently set up in our laboratory. The measured ions are the product ions at $\mathrm{m} / \mathrm{z}, 297$ and $\mathrm{m} / \mathrm{z} 303$ derived from the [M-181] ${ }^{-}$precursor ions $(\mathrm{m} / \mathrm{z}, 567$ and $\mathrm{m} / \mathrm{z}$ 573) produced from oxidized EPA and the $\mathrm{PGF}_{2 \alpha}-\mathrm{d}_{4}$, respectively.

According to our previous paper (Signorini et al. 2009), for $\mathrm{F}_{4}$-NeuroPs, the measured ions were the product ions at $\mathrm{m} / \mathrm{z}, 323$ and $\mathrm{m} / \mathrm{z} 303$ derived from the [M-181] ${ }^{-}$precursor ions $(\mathrm{m} / \mathrm{z} 593$ and $\mathrm{m} / \mathrm{z}$ 573) produced from oxidized DHA and the $\mathrm{PGF}_{2 \alpha}-\mathrm{d}_{4}$, respectively, and for $\mathrm{F}_{2}$-dihomo-IsoPs, the measured ions were the product ions at $m / z 327$ and $\mathrm{m} / \mathrm{z} 303$ derived from the $[\mathrm{M}-181]^{-}$precursor ions $(\mathrm{m} / \mathrm{z} 597$ and $m / z$ 573) produced from the derivatized ent $-7(R S)-\mathrm{F}_{2 \mathrm{t}^{-}}$ dihomo-IsoP, 17- $\mathrm{F}_{2 \mathrm{t}}$-dihomo-IsoP (De Felice et al. 2011), and the $\mathrm{PGF}_{2 \alpha}-\mathrm{d}_{4}$, respectively.

Data analysis

All variables were tested for normal distribution (D'Agostino-Pearson test), and data were presented as either means \pm standard deviation (SD) or \pm standard error of the means (SE) for normally distributed variables or medians means with 25th-75th inter-quartile range for nonnormally distributed data. Differences between groups were evaluated using independent-sample $t$ test (continuous normally distributed data), Mann-Whitney rank sum test (continuous nonnormally distributed data), chi-square statistics (categorical variables with minimum number of cases per cell $\geq 5$ ) of Fisher's exact test (categorical variables with minimum number of cases per cell $<5$ ), one-way analysis of variance (ANOVA), Student-Newman-Keuls post hoc test, or Kruskal-Wallis test. Two-tailed $P$ values of $<0.05$ were considered significant if not otherwise specified. Correction for multiple comparisons was made (Bonferroni's correction). The MedCalc version 12.1.4 statistical software package (MedCalc Software, Mariakerke, Belgium) was used.

\section{Results}

Primary outcomes

A significant reduction in CSS was observed in the $\omega-3$ PUFAs-treated RTT subpopulation, as compared to the untreated patients group (Fig. 1).

In particular, significant improvements were observed for motor/independent sitting, ambulation, hands use, nonverbal communication, and respiratory dysfunction, while a statistically nonsignificant trend was observed for language $(P=0.0649)$ and not significant changes for the other individual manifestations included in the CSS $(P \geq 0.8182)$ (Table 1). In the supplemented group, visible effects in nonverbal communication and motor function and coordination after $\omega$-3 PUFAs fish oil are shown in a short video clip edited (editing: L.D.F.) on the basis of parents' home movie images (enclosed video clip; see supplementary material). Neither significant side effects nor compliance problems related to $\omega$-3 PUFAs-containing fish oil administration were observed during all the time of the study.

Secondary outcomes

A marked decrease in plasma $\mathrm{F}_{2}$-dihomo-IsoPs $(-86.3 \%$, $P<0.0001), \quad \mathrm{F}_{3}$-IsoPs $\quad(-55.15, \quad P=0.0464), \quad$ NPBI

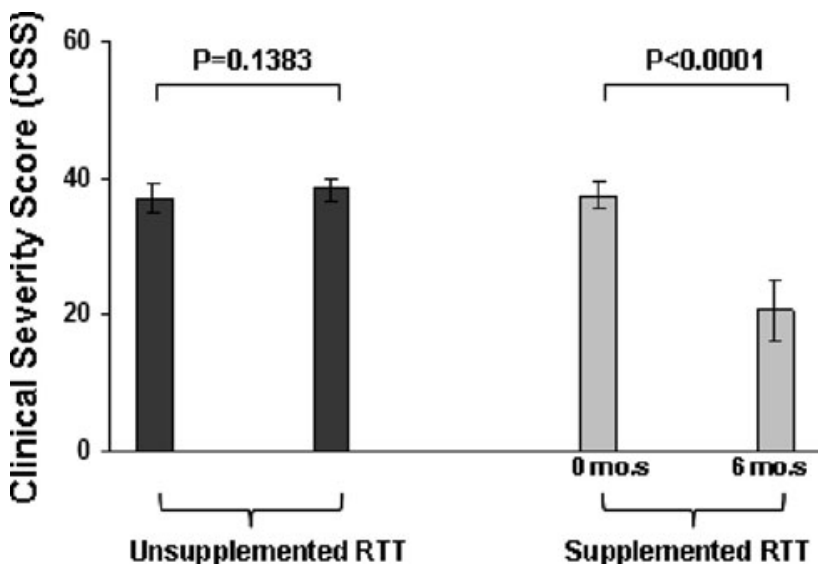

Fig. 1 Clinical Severity changes following 6-month $\omega$-3 PUFAs supplementation in stage I RTT patients (Total Clinical Severity Score, CSS). CSS was assessed according to Neul et al. 2008. The theoretical maximum CSS is 58 (see E-Table 2 of Neul et al. 2008) 
Table 1 Clinical severity score (CSS) changes following 6-month $\omega$-3 PUFAs supplementation in stage I RTT patients (individual items)

The values are medians and inter-quartile ranges. CSS was assessed according to Neul et al. 2008. Specific mutations in methyl-CpG-binding protein 2 confer different severity in Rett syndrome

\begin{tabular}{llll}
\hline Clinical manifestation & Severity Score & $P$ value \\
\cline { 2 - 4 } & $\begin{array}{l}\text { Before } \omega-3 \text { PUFAs } \\
\text { supplementation }\end{array}$ & $\begin{array}{l}\text { After } \omega-3 \text { PUFAs } \\
\text { supplementation } \\
(6 \text { months })\end{array}$ & \\
\hline Age of onset of regression & $4[4-4]$ & $4[4-4]$ & 1.0 \\
Somatic growth & $1.5[1-2]$ & $1[1-2]$ & 0.8182 \\
Head growth & $3[3-3]$ & $3[3-3]$ & 1.0 \\
Motor/independent sitting & $4[4-4]$ & $0[0-1]$ & 0.0087 \\
Ambulation & $5[5-5]$ & $1[1-4]$ & 0.0152 \\
Hand use & $4[4-4]$ & $2[2-2]$ & 0.0022 \\
Scoliosis & $0[0-0]$ & $0[0-0]$ & 1.0 \\
Language & $4[4-4]$ & $3[3-4]$ & 0.0649 \\
Nonverbal communication & $5[5-5]$ & $0[0-1]$ & 0.0022 \\
Respiratory dysfunction & $4[4-4]$ & $1[0-1]$ & $<0.0001$ \\
Autonomic symptoms & $0[0-0]$ & $0[0-0]$ & 1.0 \\
Onset of stereotypies & $4[4-4]$ & $4[4-4]$ & 1.0 \\
Epilepsy/seizures & $0[0-0]$ & $0[0-0]$ & 1.0 \\
\hline
\end{tabular}

$(-42.2 \%, P=0.0005), \mathrm{F}_{4}$-NeuroPs $(-40.3 \%, P=0.0437)$, and intraerythrocyte-NPBI $(-46.3 \%, P=0.0007)$ was observed in the treated group, while no significant difference was found regarding $\mathrm{F}_{2}$-IsoPs $(+10.2 \%, P=0.16)$. Following $\omega$-3 PUFAs supplementation, levels of intraerythrocyte-NPBI and $\mathrm{F}_{3}$-IsoPs returned to the values range of gender- and age-matched healthy controls.

On the other hand, no significant differences in any of the examined O.S. markers were observed in the untreated group ( $P \geq 0.29$ ) (Fig. 2).

Study design notes

We decided to analyze exclusively stage I patients on the conceptual basis that a potentially effective intervention in RTT should be started as earlier as possible, that is, soon after the clinical and genetic diagnosis (stage I). The short duration of stage I prevents us to carry out a crossover design. We also decided, at this phase of the study, not to include a placebo arm for ethical reasons, since our prior research (Signorini et al. 2011; Leoncini et al. 2011) had already shown a clinical and biochemical improvement following oral supplementation with DHA + EPA ethyl esters.

\section{Discussion}

Our data indicate for the first time a significant reduction in the clinical severity and a partial rescue of clinical symptoms in girls with stage I RTT following a 6 months supplementation with $\omega-3$ PUFAs oil. In particular, motor-related signs, nonverbal communication deficits, and breathing abnormalities were significantly decreased compared to agematched untreated patients. In the treated patients group, the observed clinical improvement was found to be associated with a significant decrease in the circulating O.S./lipid peroxidation markers levels. In our study, we observed a decrease in the plasma levels of $\mathrm{F}_{3}$-IsoPs, $\mathrm{F}_{2}$-dihomo-IsoPs, and $\mathrm{F}_{4}$-NeuroPs, whereas $\mathrm{F}_{2}$-IsoPs levels were unchanged. Our hypothesis is that the decreased $\mathrm{F}_{2}$-dihomo-IsoPs, $\mathrm{F}_{3^{-}}$IsoPs, and $\mathrm{F}_{4}$-NeuroPs plasma levels would likely reflect the specific clinical and biological events predominating in the patients during this early stage and that include neuronal membrane oxidative insult ( $\mathrm{F}_{4}$-NeuroPs) and a previously unrecognized oxidative-driven brain white matter damage ( $\mathrm{F}_{2}$-dihomo-IsoPs). Conversely, $\mathrm{F}_{2}$-IsoPs, given the ubiquitous AA distribution, are considered an index of generalized systemic lipid peroxidation, and it is possible that to reach a significant change in this parameter, we would need to treat subjects for a longer period, as we have shown in our previous report on the effects of $\omega$-3 PUFAs (ethyl esters preparation; EPA-to-DHA ratio of about 1.5; average dose: 20-40 mg/kg b.w./day; duration 12 months), on the levels of a number of plasma and red blood cell markers of O.S. in RTT patients with more advanced clinical stages (stages III and IV), in whom we had observed a significant reduction in plasma $F_{2}$-IsoPs (see Figure 4 in Leoncini $S$. et al. 2011). Although we should always keep in mind the "association is not causation" concept, our findings indicate a close relationship between levels of circulating O.S. biomarkers in RTT patients and presence of the symptoms, strongly supporting the concept that oxidative damage plays a previously unrecognized key role in the pathogenesis of RTT/MeCP2 deficiency. Our prior research had already demonstrated a partial clinical and biochemical improvement in patients 

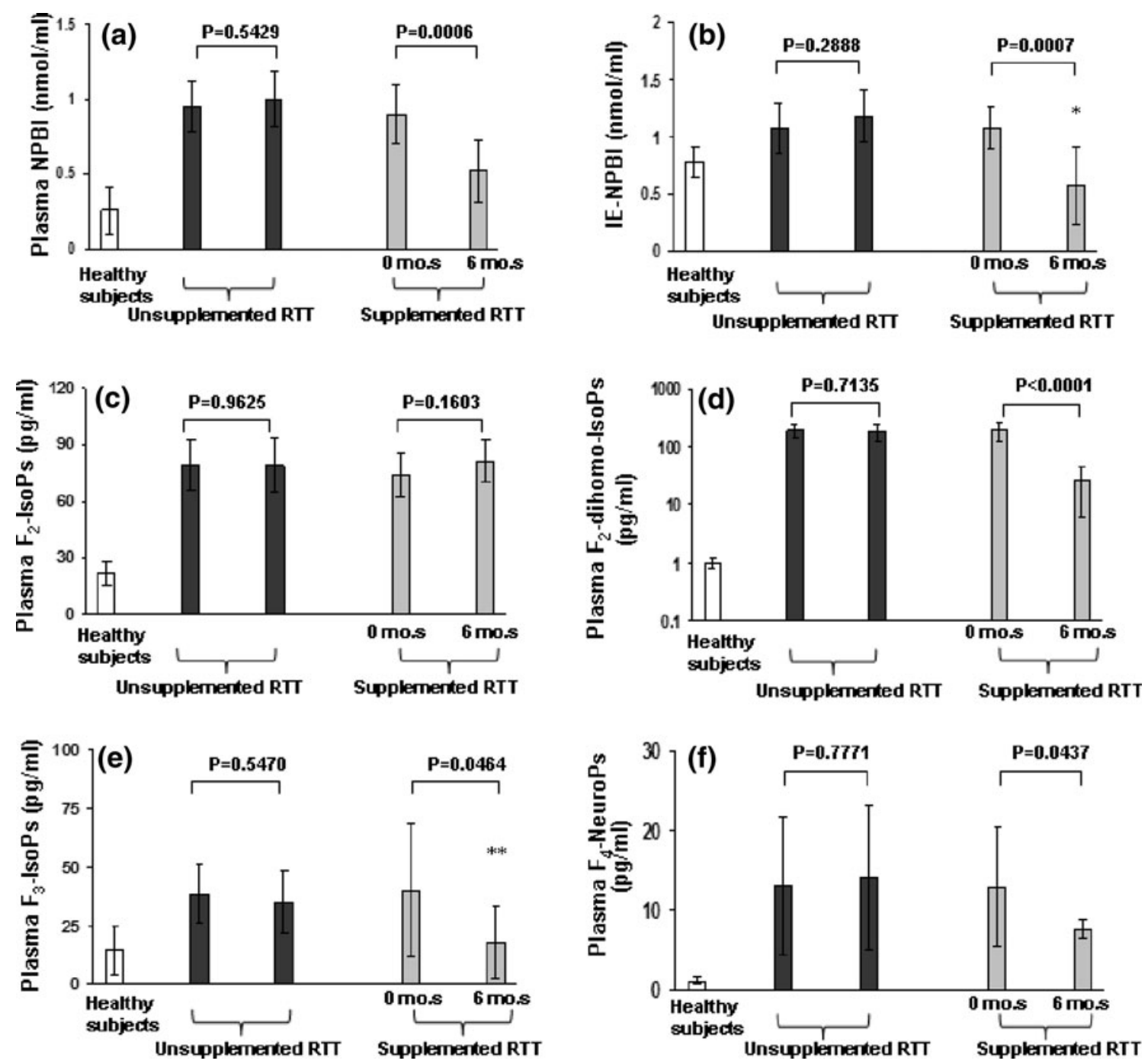

Fig. 2 Nonprotein bound iron and isoprostanes levels changes following 6-month $\omega$-3 PUFAs supplementation in stage I RTT patients. Plasma $\mathrm{F}_{2}$-dihomo-IsoP values (mean $\pm \mathrm{SE}$ ) are presented in logarithmic scale. Legend P-NPBI, plasma NPBI; IE-NPBI, intra-

erythrocyte NPBI; mo.s, months. All the differences between treated RTT (before and after), untreated RTT (time 0 and time 6 months), and healthy controls were statistically significant. $* P=0.10$ versus healthy controls; $* * P=0.567$ versus healthy controls

with RTT following supplementation with DHA plus EPA ethyl esters (Signorini et al. 2011; Leoncini et al. 2011), although no rescue of major symptoms, such as-for instance- the loss of acquired purposeful hand skills, have been observed.

In the present study, dose-finding for the administered PUFAs-containing fish oil was based on empirical grounds and on the clinical intuition of an experienced physician with specific expertise in RTT (J.H.). Although the daily dose of $\omega-3$ PUFAs per $\mathrm{kg}$ of body weight here used was about sevenfold higher (EPA: $7.3 \pm 3.4$ fold; DHA: $6.8 \pm 3.2$ fold) than that reported in our prior studies evaluating RTT patients in later disease stages using EPA plus DHA ethyl esters (Leoncini et al. 2011; Signorini et al. 2011), we did not observe any safety or compliance problems.

Our findings are surprising since a true rescue of the disease is to date known to be obtainable only in animal models through restoration of the MeCP2 function, such as by reexpressing the $\mathrm{MeCP} 2$ gene in the neurons and glia of MeCP2-null mice (Guy et al. 2007), while a partial rescue in RTT mice has been reported by exogenous IGF-1 (Tropea et al. 2009).

The concept of RTT as a pure neuronal disease has been recently challenged with results implicating the involvement of glial cells in the pathogenesis of MeCP2 deficiency (Maezawa et al. 2009; Ballas et al. 2009; Zoghbi 2009). An involvement of the glia appears to be in line with the data of the present study, as well as with a prior report in which we have demonstrated in a 2-order of magnitude increase in $\mathrm{F}_{2}$-dihomo-IsoPs in RTT stage I patients (De Felice et al. 2011), likely reflecting a white matter oxidative damage 
(VanRollins et al. 2008). These isoprostanes are the oxidation products of AdA, a specific component of myelin also present in several organs and tissues (Sastry 1985; VanRollins et al. 2008; Sprecher et al. 1982). Some neurologic signs in stage I RTT, such as cognitive decline up to dementia, motor impairment, aphasia, and apraxia, curiously overlap with those of X-linked adreno-leukodystrophy (X-ALD), a rare inherited disorder mainly affecting the brain white matter in males, and leading to progressive brain damage, failure of the adrenal glands, and eventually death (Cappa et al. 2011). Interestingly, evidence of early O.S.-driven damage has been reported also in X-ALD (Fourcade et al. 2008; Galino et al. 2011), as well as improvement of clinical symptoms in the patients (Kawashima et al. 2011), and halting of axonal degeneration in an X-ALD mouse model following treatment with antioxidants (López-Erauskin et al. 2011), or exogenous IGF-1 (Mastroeni et al. 2009), thus impressively extending the overlap between RTT and X-ALD. Thus, it is conceivable that the improvements in motor function (i.e., motor/sitting, hand use, and independent ambulation) and attention (i.e., nonverbal communication) observed in early RTT following $\omega$-3 PUFAs supplementation may be, at least partially, related to a partial rescue of white matter damage component at this stage of the disease. Moreover, it is interesting to note that a previously unrecognized white matter damage is present and related to language impairment (Mahmood et al. 2010; Zoghbi 2009).

In our case series, verbal language improved after $\omega-3$ PUFAs 6-month oral supplementation although the difference with the language severity score at time 0 did not reach the statistical significance level $(P=0.0649)$. As a consequence, it is possible that a partial rescue of white matter damage at an early stage of the disease could be reflected by the observed marked improvement in the nonverbal language.

On the other hand, lack of significant changes in both somatic and specifically head growth was likely not to be expected, given the relatively short-time duration of treatment.

$\omega-3$ PUFAs are known antioxidants with multiple effects, with an emerging role in neuroprotection in several human conditions, including psychiatric disorders $(\mathrm{McNa}-$ mara 2010), and animal experimental settings (Zhang et al. 2011; Chang et al. 2009; Bazan 2007). However, the molecular mechanisms of $\omega$-3 PUFAs action remain only partially understood and include changes in membrane structures and gene expression, direct interactions with ion channels, and alterations in eicosanoid biosynthesis (Chapkin et al. 2008; Jump 2002; Deckelbaum et al. 2006; Xiao et al. 2005; Calder 2006; Serhan et al. 2008). EPA and DHA are key $\omega-3$ PUFAs, known to influence the physical nature of cell membranes, as well as membrane protein-mediated responses, lipid mediator generation, cell signaling, gene expression (Calder and Yaqoob 2009), and competition with AA for binding and conversion by cyclooxygenases and lipoxygenases, thus modulating the production of bioactive prostanoids and leukotrienes (Schmitz and Ecker 2008; Wada et al. 2007). At the same time, they have been reported to compete with AA for the conversion by cytochrome P450 enzymes, thus resulting in the formation of alternative, physiologically active, metabolites, given that cytochrome P450 enzymes are known to efficiently convert EPA and DHA to novel epoxy and hydroxy metabolites (17,18-epoxyeicosatetraenoic, and 19,20-epoxydocosapentaenoic acid, respectively) (Arnold et al. 2010), which could mediate some of the beneficial effects observed in the RTT patients. In particular, DHA is an essential constituent of the nervous tissue (Soderberg et al. 1991) that is necessary for ion channels, receptors, and transporters to maintain their proper physical conformation that may be involved in memory formation, excitable membrane function, and neuroprotection, as it is known to represent the precursor of neuroprotectin D1 (NPD1), which, in turn, downregulates apoptosis and promotes cell survival (Gamoh et al. 1999; McGahon et al. 1999; Belayev et al. 2005; Serhan et al. 2006).

The reported interactions not only result in a partial replacement of the classical AA-derived eicosanoids by their less potent $\omega$-3 counterparts, but also produce novel lipid mediators termed "resolvins" and "protectins" that have highly potent anti-inflammatory and pro-resolution properties (Serhan et al. 2008).

Contrary to expectation, the exogenous administration of the chemical precursors of the peroxidation products $\mathrm{F}_{3}$-IsoPs and $\mathrm{F}_{4}$-NeuroPs - that is EPA and DHA, respectively-paradoxically led in our patients to a reduction, instead of the predictable increase in these specific IsoPs. This finding may generate the interesting concept that the increased $\mathrm{F}_{3}$-IsoPs and $\mathrm{F}_{4}$-NeuroPs detectable in early RTT are not only due to a simple, ROS-mediated, nonspecific peroxidation of EPA and DHA, as, if this were the case, their exogenous administration should increase, rather than decrease, these peroxidation products. Therefore, it is conceivable that the enhanced O.S. and lipid peroxidation observed in RTT patients could derive from a defect of regulation of potential $\omega-3$ PUFAs targets, such as ion channels, and eicosanoid biosynthesis. It is interesting to note that an impaired $\mathrm{K}^{+}$channel dysfunction has been previously reported in a mouse model of RTT during hypoxic conditions (Kron and Müller 2010) and that a chronic mild hypoxia is a landmark feature of typical RTT (De Felice et al. 2009).

There is a current debate on the generation of secondary metabolites from administered oxidizable fatty acids precursors. It is conceivable that several factors may affect $\omega$ - 
3 PUFAs oxidation, likely including individual oxidation rates, chemical stability of the commercial product, the administration route, the specific clinical pathology, bioavailability and fatty acid composition, and, last but not least, the oxygenation and oxidative status of the recipient. One of the rare examples we are aware of is a study by Yin et al. on the administration of $\omega$-3 PUFAs-containing fish oil in an experimental model of allergic lung inflammation, in which the DHA and EPA oxidation end-products (i.e., $\mathrm{F}_{4}$-NeuroPs and $\mathrm{F}_{3}$-IsoPs, respectively) have been monitored and found to be increased (Yin et al. 2009). However, this result is applicable to a quite different recipient (mouse vs. human) and disease (pulmonary inflammation vs. RTT) from those described in our study. However, it should be emphasized that RTT is a quite peculiar pathological condition with enhanced in vivo lipid peroxidation and decreased oxygen availability (De Felice et al. 2009). In addition, it is demonstrable that $\omega$-3 PUFAs prevent lipoperoxidation in the livers of diabetic rats fed on a high-fat diet (de Assis et al. 2012) and that EPA plus DHA do not generate $\mathrm{F}_{3}$-IsoPs and $\mathrm{F}_{4}$-IsoPs in either obese-dyslipidemic or hypertensive type 2 diabetic patients (Mas et al. 2010).

Given that, for this particular progressive disease, it is plausible that an earlier intervention is more likely to possibly potentially change the natural course of the disease than a later intervention, the present pilot study could be of importance for designing future placebo-controlled randomized multicenter trials specifically targeted at the early stage of the disease and with a particular focus on the long-term outcomes.

While our findings do not prove that $\omega$-3 PUFAs are a therapy for RTT, they strongly suggest that these natural compounds, currently believed to be simple "dietary supplements," could possess a pharmacologic action, at least as far as it concerns the examined pathology. At the same time, the partial clinical rescue here observed sheds further light into the current state of evidence on the mechanisms behind RTT and, in particular, on the biochemical events related to $\mathrm{MeCP} 2$ deficiency. In this regard, 7,8-dihydroxyflavone, a small polyphenolic molecule, has been recently reported to improve lifespan, and partially rescue motor deficits, and the breathing dysfunction in MeCP2 mutant mice (MeCP2 $2^{\text {tm1.1Jae }}$ ) (Johnson et al. in press). Although the authors of the latter study hypothetically relate the observed beneficial effects to the brain-derived neurotrophic factor (BDNF) receptor (TrkB) agonist action of the molecule, it cannot be ruled out that part of the observed beneficial effects might be partially attributed to its well-known antioxidant activity (Chen et al. 2011). The likely relevance of the antioxidant activity of 7,8-dihydroxyflavone in determining symptomatic improvement in the RTT mouse model is further suggested by the striking similarity with the partial clinical rescue, mainly in the motor and respiratory functions, here observed following $\omega$-3 PUFAs supplementation in RTT girls. Our different perspective on the 7,8-dihydroxyflavone beneficial effects would further reinforce the hypothesis that O.S. plays a key role in the intimate pathogenic mechanisms of this genetically determined condition and suggests that the modulation of the O.S. derangement in RTT by a dietary intervention might potentially hit several different molecular targets (i.e., either lipid peroxidation and hemoglobin auto-oxidation, or BDNF receptors), thus possibly modifying the natural progression of the disease.

Of course, several outstanding open questions about $\omega$-3 PUFAs use in RTT would remain, with a particular focus on the most proper dosage, treatment duration, chemical formulation (Anderson and Ma 2009), as well as a better understanding of their organ/cellular fate and a possible active role for their secondary metabolites (Arnold et al. 2010).

Although our results should be taken with caution, due to the intrinsic limitations of a small-sized pilot study on a genetic condition notoriously characterized by great clinical variability, the effects observed here for a short-lived randomized single-blind trial of a high dose of $\omega$-3 PUFAs in early RTT, to date an incurable disease, appear to be unequivocal and could drive a better quality of life care for these patients.

Acknowledgments This paper is dedicated to professional singer Matteo Setti (Reggio Emilia, Italy, official web site: http://www. matteosetti.it) who surprisingly inspired and triggered our studies on hypoxia and oxidative stress in Rett syndrome. We thank the Azienda Ospedaliera Universitaria Senese Hospital Administration for purchasing the mass spectrometer, and Roberto Faleri (Central Medical Library, University of Siena, Siena, Italy) for online bibliographic assistance. We acknowledge the Medical Genetics Unit of the Siena University (Head: Prof. Alessandra Renieri) for gene mutation analysis. We are greatly indebted to all the families of Rett syndrome patients who kindly participated in the study and gave permission to use personal photographic images and homemade video clips for scientific documentation purposes. The present research project has been funded by Tuscany Region and by the Toscana Life Sciences [Orphan_0108 Call; title: "Nuovi approcci terapeutici nella sindrome di Rett"], Siena, Italy. TD and JMG are grateful to the University of Montpellier I (BQR-2008 and 2011) and INRA (AlimH-2008-2010) for financial support.

Conflict of interest The authors are not aware of any affiliations, memberships, funding, or financial holdings that might affect the objectivity of this paper.

\section{References}

Amir RE, Van den Veyver IB, Wan M, Tran CQ, Francke U, Zoghbi HY (1999) Rett syndrome is caused by mutations in X-linked MECP2, encoding methyl-CpG-binding protein 2. Nat Genet 23:185-188 
Anderson BM, Ma DWL (2009) Are all n-3 polyunsaturated fatty acids created equal? Lipids Health Dis 8:33

Ariani F, Hayek G, Rondinella D, Artuso R, Mencarelli MA, Spanhol-Rosseto A, Pollazzon M, Buoni S, Spiga O, Ricciardi S, Meloni I, Longo I, Mari F, Broccoli V, Zappella M, Renieri A (2008) FOXG1 is responsible for the congenital variant of Rett syndrome. Am J Hum Genet 83:89-93

Arnold C, Markovic M, Blossey K, Wallukat G, Fischer R, Dechend R, Konkel A, von Schacky C, Luft FC, Muller DN, Rothe M, Schunck WH (2010) Arachidonic acid-metabolizing cytochrome P450 enzymes are targets of 3 fatty acids. J Biol Chem 285:32720-32733

Ballas N, Lioy DT, Grunseich C, Mandel G (2009) Non-cell autonomous influence of $\mathrm{MeCP} 2$-deficient glia on neuronal dendritic morphology. Nat Neurosci 12:311-317

Bazan NG (2007) Omega-3 fatty acids, pro-inflammatory signaling and neuroprotection. Curr Opin Clin Nutr Metab Care 10:136-141

Belayev L, Marcheselli VL, Khoutorova L, Rodriguez de Turco EB, Busto R, Ginsberg MD, Bazan NG (2005) Docosahexaenoic acid complexed to albumin elicits high-grade ischemic neuroprotection. Stroke 36:118-123

Belayev L, Khoutorova L, Atkins KD, Bazan NG (2009) Robust docosahexaenoic acid-mediated neuroprotection in a rat model of transient, focal cerebral ischemia. Stroke 40:3121-3126

Ben-Shachar S, Chahrour M, Thaller C, Shaw CA, Zoghbi HY (2009) Mouse models of $\mathrm{MeCP} 2$ disorders share gene expression changes in the cerebellum and hypothalamus. Hum Mol Genet 18:2431-2442

Calder PC (2006) n-3 polyunsaturated fatty acids, inflammation, and inflammatory diseases. Am J Clin Nutr 83:1505S-1519S

Calder PC, Yaqoob P (2009) Understanding omega-3 polyunsaturated fatty acids. Postgrad Med 121:148-157

Cappa M, Bizzarri C, Vollono C, Petroni A, Banni S (2011) Adrenoleukodystrophy. Endocr Dev 20:149-160

Chahrour M, Zoghbi HY (2007) The story of Rett syndrome: from clinic to neurobiology. Neuron 56:422-437

Chahrour M, Jung SY, Shaw C, Zhou X, Wong ST, Qin J, Zoghbi HY (2008) MeCP2, a key contributor to neurological disease, activates and represses transcription. Science 320:1224-1229

Chang CY, Ke DS, Chen JY (2009) Essential fatty acids and human brain. Acta Neurol Taiwan 18:231-241

Chao HT, Chen H, Samaco RC, Xue M, Chahrour M, Yoo J, Neul JL, Gong S, Lu HC, Heintz N, Ekker M, Rubenstein JL, Noebels JL, Rosenmund C, Zoghbi HY (2010) Dysfunction in GABA signalling mediates autism-like stereotypies and Rett syndrome phenotypes. Nature 468:263-269

Chapkin RS, McMurray DN, Davidso LA, Patil BS, Fan YY, Lupton JR (2008) Bioactive dietary long-chain fatty acids: emerging mechanisms of action. Br J Nutr 100:1152-1157

Chen J, Chua KW, Chua CC, Yu H, Pei A, Chua BH, Hamdy RC, Xu X, Liu CF (2011) Antioxidant activity of 7,8-dihydroxyflavone provides neuroprotection against glutamate-induced toxicity. Neurosci Lett 499:181-185

Cobb S, Guy J, Bird A (2010) Reversibility of functional deficits in experimental models of Rett syndrome. Biochem Soc Trans $38: 498-506$

Collins AL, Levenson JM, Vilaythong AP, Richman R, Armstrong DL, Noebels JL, David Sweatt J, Zoghbi HY (2004) Mild overexpression of $\mathrm{MeCP} 2$ causes a progressive neurological disorder in mice. Hum Mol Genet 13:2679-2689

Comporti M, Signorini C, Buonocore G, Ciccoli L (2002) Iron release, oxidative stress and erythrocyte ageing. Free Radic Biol Med 32:568-576

Comporti M, Signorini C, Arezzini B, Vecchio D, Monaco B, Gardi C (2008) F2-isoprostanes are not just markers of oxidative stress. Free Radic Biol Med 44:247-256 de Assis AM, Rech A, Longoni A, Rotta LN, Denardin CC, Pasquali MA, Souza DO, Perry ML, Moreira JC (2012) $\Omega 3$-Polyunsaturated fatty acids prevent lipoperoxidation, modulate antioxidant enzymes, and reduce lipid content but do not alter glycogen metabolism in the livers of diabetic rats fed on a high fat thermolyzed diet. Mol Cell Biochem 361:151-160

De Felice C, Ciccoli L, Leoncini S, Signorini C, Rossi M, Vannuccini L, Guazzi G, Latini G, Comporti M, Valacchi G, Hayek J (2009) Systemic oxidative stress in classic Rett syndrome. Free Radic Biol Med 47:440-448

De Felice C, Signorini C, Durand T, Oger C, Guy A, Bultel-Poncé V, Galano JM, Ciccoli L, Leoncini S, D'Esposito M, Filosa S, Pecorelli A, Valacchi G, Hayek J (2011) F2-dihomo-isoprostanes as potential early biomarkers of lipid oxidative damage in Rett syndrome. J Lipid Res 52:2287-2297

Deckelbaum RJ, Worgall TS, Seo T (2006) n-3 fatty acids and gene expression. Am J Clin Nutr 83:1520S-1525S

El-Ansary AK, Al-Daihan SK, El-Gezeery AR (2011) On the protective effect of omega-3 against propionic acid-induced neurotoxicity in rat pups. Lipids Health Dis 10:142

Fourcade S, López-Erauskin J, Galino J, Duval C, Naudi A, Jove M, Kemp S, Villarroya F, Ferrer I, Pamplona R, Portero-Otin M, Pujol A (2008) Early oxidative damage underlying neurodegeneration in X- adrenoleukodystrophy. Hum Mol Genet $17: 1762-1773$

Galino J, Ruiz M, Fourcade S, Schlüter A, López-Erauskin J, Guilera C, Jove M, Naudi A, García-Arumí E, Andreu AL, Starkov AA, Pamplona R, Ferrer I, Portero-Otin M, Pujol A (2011) Oxidative damage compromises energy metabolism in the axonal degeneration mouse model of X-adrenoleukodystrophy. Antioxid Redox Signal 15:2095-2107

Gamoh S, Hashimoto M, Sugioka K, Shahdat Hossain M, Hata N, Misawa Y, Masumura S (1999) Chronic administration of docosahexaenoic acid improves reference memory-related learning ability in young rats. Neuroscience 93:237-241

Guy J, Gan J, Selfridge J, Cobb S, Bird A (2007) Reversal of neurological defects in a mouse model of Rett syndrome. Science 315:1143-1147

Guy J, Cheval H, Selfridge J, Bird A (2011) The role of MeCP2 in the brain. Annu Rev Cell Dev Biol 27:631-652

Hagberg B, Aicardi J, Dias K, Ramos O (1983) A progressive syndrome of autism, dementia, ataxia, and loss of purposeful hand use in girls: Rett's syndrome: report of 35 cases. Ann Neurol 14:471-479

Halliwell B, Gutteridge J (1999) Free radicals, other reactive species and disease. In: Halliwell B, Gutteridge J (eds) Free radicals in biology and medicine. Clarendon Press, Oxford, pp 617-783

Johnson RA, Lam M, Punzo AM, Li H, Lin BR, Ye K, Mitchell GS, Chang Q (2011) 7,8-dihydroxyflavone (7,8-DHF) exhibits therapeutic efficacy in a mouse model of Rett syndrome. J Appl Physiol. doi:10.1152/japplphysiol.01361

Jump DB (2002) The biochemistry of $n-3$ polyunsaturated fatty acids. J Biol Chem 277:8755-8758

Kadiiska MB, Gladen BC, Baird DD, Germolec D, Graham LB, Parker CE, Nyska A, Wachsman JT, Ames BN, Basu S, Brot N, Fitzgerald GA, Floyd RA, George M, Heinecke JW, Hatch GE, Hensley K, Lawson JA, Marnett LJ, Morrow JD, Murray DM, Plastaras J, Roberts LJ, Rokach J, Shigenaga MK, Sohal RS, Sun J, Tice RR, Van Thiel DH, Wellner D, Walter PB, Tomer KB, Mason RP, Barrett JC (2005) Biomarkers of oxidative stress study II: are oxidation products of lipids, proteins, and DNA markers of $\mathrm{CCl} 4$ poisoning? Free Radic Biol Med 38:698-710

Kawashima H, Nishimata S, Ishii C, Yamanaka G, Kashiwagi Y, Takekuma K, Hoshika A, Watanabe Y (2011) New treatment of free-radical scavenger in adrenoleukodystrophy. J Clin Pharm Ther 36:412-415 
Kris-Etherton PM, Harris WS, Appel LJ; American Heart Association. Nutrition Committee (2002) Fish consumption, fish oil, omega-3 fatty acids, and cardiovascular disease. Circulation 106:2747-2757

Kron M, Müller M (2010) Impaired hippocampal $\mathrm{Ca}^{2+}$ homeostasis and concomitant $\mathrm{K}^{+}$channel dysfunction in a mouse model of Rett syndrome during anoxia. Neuroscience 171:300-315

Leoncini S, De Felice C, Signorini C, Pecorelli A, Durand T, Valacchi G, Ciccoli L, Hayek J (2011) Oxidative stress in Rett syndrome: natural history, genotype, and variants. Redox Rep 16:145-153

Lien EL (2009) Toxicology and safety of DHA. Prostaglandins Leukot Essent Fatty Acids 81:125-132

López-Erauskin J, Fourcade S, Galino J, Ruiz M, Schlüter A, Naudi A, Jove M, Portero-Otin M, Pamplona R, Ferrer I, Pujol A (2011) Antioxidants halt axonal degeneration in a mouse model of X-adrenoleukodystrophy. Ann Neurol 70:84-92

Macdonald JL, Verster A, Berndt A, Roskams AJ (2010) MBD2 and $\mathrm{MeCP} 2$ regulate distinct transitions in the stage-specific differentiation of olfactory receptor neurons. Mol Cell Neurosci 44:55-67

Maezawa I, Swanberg S, Harvey D, LaSalle JM, Jin LW (2009) Rett syndrome astrocytes are abnormal and spread MeCP2 deficiency through gap junctions. J Neurosci 29:5051-5061

Mahmood A, Bibat G, Zhan AL, Izbudak I, Farage L, Horska A, Mori S, Naidu S (2010) White matter impairment in Rett syndrome: diffusion tensor imaging study with clinical correlations. AJNR Am J Neuroradiol 31:295-299

Marchetto MC, Carromeu C, Acab A, Yu D, Yeo GW, Mu Y, Chen G, Gage FH, Muotri AR (2010) A model for neural development and treatment of Rett syndrome using human induced pluripotent stem cells. Cell 143:527-539

Mari F, Azimonti S, Bertani I, Bolognese F, Colombo E, Caselli R, Scala E, Longo I, Grosso S, Pescucci C, Ariani F, Hayek G, Balestri P, Bergo A, Badaracco G, Zappella M, Broccoli V, Renieri A, Kilstrup-Nielsen C, Landsberger N (2005) CDKL5 belongs to the same molecular pathway of MeCP2 and it is responsible for the early-onset seizure variant of Rett syndrome. Hum Mol Genet 14:1935-1946

Mas E, Woodman RJ, Burke V, Puddey IB, Beilin LJ, Durand T, Mori TA (2010) The omega-3 fatty acids EPA and DHA decrease plasma $\mathrm{F}(2)$-isoprostanes: Results from two placebo-controlled interventions. Free Radic Res 44:983-990

Mastroeni R, Bensadoun JC, Charvin D, Aebischer P, Pujol A, Raoul C (2009) Insulin-like growth factor-1 and neurotrophin-3 gene therapy prevents motor decline in an X-linked adrenoleukodystrophy mouse model. Ann Neurol 66:117-122

Matarazzo MR, De Bonis ML, Vacca M, Della Ragione F, D’Esposito M (2009) Lessons from two human chromatin diseases, ICF syndrome and Rett syndrome. Int $\mathrm{J}$ Biochem Cell Biol 41:117-126

McGahon BM, Martin DS, Horrobin DF, Lynch MA (1999) Agerelated changes in synaptic function: analysis of the effect of dietary supplementation with omega-3 fatty acids. Neuroscience 94:305-314

McNamara RK (2010) DHA deficiency and prefrontal cortex neuropathology in recurrent affective disorders. J Nutr 140:864-868

Montine KS, Quinn JF, Zhang J, Fessel JP, Roberts LJ 2nd, Morrow JD, Montine TJ (2004) Isoprostanes and related products of lipid peroxidation in neurodegenerative diseases. Chem Phys Lipids 128:117-124

Montuschi P, Barnes PJ, Roberts LJ (2004) Isoprostanes: markers and mediators of oxidative stress. FASEB J 18:1791-1800

Morrow JD, Roberts LJ (1997) The isoprostanes: unique bioactive products of lipid peroxidation. Prog Lipid Res 36:1-21
Morrow JD, Hill KE, Burk RF, Nammour TM, Badr KF, Roberts LJ (1990) A series of prostaglandin F2-like compounds are produced in vivo in humans by a non-cyclooxygenase, free radical-catalyzed mechanism. Proc Natl Acad Sci USA 87:9383-9387

Naidu S, Johnston MV (2011) Neurodevelopmental disorders: clinical criteria for Rett syndrome. Nat Rev Neurol 7:312-314

Neul JL, Fang P, Barrish J, Lane J, Caeg EB, Smith EO, Zoghbi H, Percy A, Glaze DG (2008) Specific mutations in methyl-CpGbinding protein 2 confer different severity in Rett syndrome. Neurology 70:1313-1321

Neul JL, Kaufmann WE, Glaze DG, Christodoulou J, Clarke AJ, BahiBuisson N, Leonard H, Bailey ME, Schanen NC, Zappella M, Renieri A, Huppke P, Percy AK (2010) Rett syndrome: revised diagnostic criteria and nomenclature. Ann Neurol 68:944-950

Nourooz-Zadeh J (2008) Key issues in F2-isoprostane analysis. Biochem Soc Trans 36:1060-1065

Nourooz-Zadeh J, Gopaul NK, Barrow S, Mallet AI, Anggard EE (1995) Analysis of F2-isoprostanes as indicators of nonenzymatic lipid peroxidation in vivo by gas chromatographymass spectrometry: development of a solid-phase extraction procedure. J Chromatogr B Biomed Appl 667:199-208

Ogier M, Wang H, Hong E, Wang Q, Greenberg ME, Katz DM (2007) Brain-derived neurotrophic factor expression and respiratory function improve after ampakine treatment in a mouse model of Rett syndrome. J Neurosci 27:10912-10917

Pecorelli A, Ciccoli L, Signorini C, Leoncini S, Giardini A, D’Esposito M, Filosa S, Hayek J, De Felice C, Valacchi G (2011) Increased levels of 4HNE-protein plasma adducts in Rett syndrome. Clin Biochem 44:368-371

Rett A (1966) On a unusual brain atrophy syndrome in hyperammonemia in childhood. Wien Med Wochenschr 116:723-726

Roberts LJ, Montine TJ, Markesbery WR, Tapper AR, Hardy P, Chemtob S, Dettbarn WD, Morrow JD (1998) Formation of isoprostane-like compounds (neuroprostanes) in vivo from docosahexaenoic acid. J Biol Chem 273:13605-13612

Roux JC, Dura E, Moncla A, Mancini J, Villard L (2007) Treatment with desipramine improbe breathing and survival in a mouse model for Rett syndrome. Eur J Neurosci 25:1915-1922

Sastry PS (1985) Lipids of nervous tissue: composition and metabolism. Prog Lipid Res 24:69-176

Schmitz G, Ecker J (2008) The opposing effects of n-3 and n-6 fatty acids. Prog Lipid Res 47:147-155

Serhan CN, Gotlinger K, Hong S, Lu Y, Siegelman J, Baer T, Yang R, Colgan SP, Petasis NA (2006) Anti-inflammatory actions of neuroprotectin D1/protectin D1 and its natural stereoisomers: assignments of dihydroxy-containing docosatrienes. J Immunol 176:1848-1859

Serhan CN, Chiang N, Van Dyke TE (2008) Resolving inflammation: dual anti-inflammatory and pro-resolution lipid mediators. Nat Rev Immunol 8:349-361

Signorini C, Comporti M, Giorgi G (2003) Ion trap tandem mass spectrometric determination of F2-isoprostanes. J Mass Spectrom 38:1067-1074

Signorini C, Ciccoli L, Leoncini S, Carloni S, Perrone S, Comporti M, Balduini W, Buonocore G (2009) Free iron, total F2-isoprostanes and total F4-neuroprostanes in a model of neonatal hypoxicischemic encephalopathy: neuroprotective effect of melatonin. J Pineal Res 46:148-154

Signorini C, De Felice C, Leoncini S, Giardini A, D’Esposito M, Filosa S, Della Ragione F, Rossi M, Pecorelli A, Valacchi G, Ciccoli L, Hayek J (2011) F4-neuroprostanes mediate neurological severity in Rett syndrome. Clin Chim Acta 412:1399-1406

Soderberg M, Edlund C, Kristensson K, Dallner G (1991) Fatty acid composition of brain phospholipids in aging and in Alzheimer's disease. Lipids 26:421-425 
Sprecher H, VanRollins M, Sun F, Wyche A, Needleman P (1982) Dihomo-prostaglandins and -thromboxane. A prostaglandin family from adrenic acid that may be preferentially synthesized in the kidney. J Biol Chem 257:3912-3918

Tropea D, Giacometti E, Wilson NR, Beard C, McCurry C, Fu DD, Flannery R, Jaenisch R, Sur M (2009) Partial reversal of Rett syndrome-like symptoms in MeCP2 mutant mice. Proc Natl Acad Sci USA 106:2029-2034

VanRollins M, Woltjer RL, Yin H, Morrow JD, Montine TJ (2008) F2-dihomo-isoprostanes arise from free radical attack on adrenic acid. J Lipid Res 49:995-1005

Viemari JC, Roux JC, Tryba AK, Saywell V, Burnet H, Pena F, Zanella S, Bevengut M, Barthelemy-Requin M, Herzing LB, Moncla A, Mancini J, Ramirez JM, Villard L, Hilaire G (2005) Mecp2 deficiency disrupts norepinephrine and respiratory systems in mice. J Neurosci 25:11521-11530

Wada M, DeLong CJ, Hong YH, Rieke CJ, Song I, Sidhu RS, Yuan C, Warnock M, Schmaier AH, Yokoyama C, Smyth EM, Wilson SJ, FitzGerald GA, Garavito RM, de Sui X, Regan JW, Smith WL (2007) Enzymes and receptors of prostaglandin pathways with arachidonic acid-derived versus eicosapentaenoic acidderived substrates and products. J Biol Chem 282:22254-22266

Wood LG, Gibson PG, Garg ML (2003) Biomarkers of lipid peroxidation, airway inflammation and asthma. Eur Respir $\mathrm{J}$ $21: 177-186$

Xiao YF, Sigg DC, Leaf A (2005) The antiarrhythmic effect of n-3 polyunsaturated fatty acids: modulation of cardiac ion channels as a potential mechanism. J Membr Biol 206:141-154

Yin H, Porter NA (2005) New insights regarding the autoxidation of polyunsaturated fatty acids. Antioxid Redox Signal 7:170-184

Yin H, Liu W, Goleniewska K, Porter NA, Morrow JD, Peebles RS (2009) Dietary supplementation of omega-3 fatty acid-containing fish oil suppresses F2-isoprostanes but enhances inflammatory cytokine response in a mouse model of ovalbumin-induced allergic lung inflammation. Free Radic Biol Med 47:622-628

Zhang W, Li P, Hu X, Zhang F, Chen J, Gao Y (2011) Omega-3 polyunsaturated fatty acids in the brain: metabolism and neuroprotection. Front Biosci 17:2653-2670

Zoghbi HY (2009) Rett syndrome: what do we know for sure? Nat Neurosci 12:239-240 